\title{
Changes of Nucleosome Frequency in Nucleolar and Non-Nucleolar Chromatin as a Function of Transcription: an Electron Microscopic Study
}

\author{
Ulrich Scheer \\ Division of Membrane Biology and Biochemistry \\ Institute of Experimental Pathology \\ German Cancer Research Center \\ 6900 Heidelberg \\ Federal Republic of Germany
}

\section{Summary}

The morphology of nucleolar and non-nucleolar (lampbrush chromosome loops) chromatin was studied in the electron microscope during states of reduced transcriptional activity in amphibian oocytes (Xenopus laevis, Triturus alpestris, T. cristatus). Reduced transcriptional activity was observed in maturing stages of oocyte development and after treatment with an inhibitor, actinomycin $D$.

Strands of nucleolar chromatin appear smooth and thin, and contain only few, if any, nucleosomal particles in the transcribed units. This is true whether they are densely or only sparsely covered with lateral ribonucleoprotein fibrils. This smooth and non-nucleosomal character is also predominant in the interspersed, apparently nontranscribed rDNA spacer regions. During inactivation, however, nucleolar chromatin frequently and progressively assumes a beaded appearance in extended fibril-free - that is, apparently nontranscribed-regions. In either full-grown oocytes or late after drug treatment, most of the nucleolar chromatin is no longer smooth and thin, but rather shows a beaded configuration indistinguishable from inactive non-nucleolar chromatin. In many chromatin strands, transitions of fibril-associated regions of smooth character into beaded regions wihout lateral fibrils are seen.

Similarly, in the non-nucleolar chromatin of the retracting lampbrush chromosome loops, reduced transcriptional activity is correlated with a change from smooth to beaded morphology. Here, however, beaded regions are also commonly found interspersed between the more or less distant bases of the lateral fibrils, the putative transcriptional complexes.

In both sorts of chromatin, detergents (in particular Sarkosyl) that remove most of the chromatin proteins including histones from the DNA axis but leave the RNA polymerases of the transcriptional complexes attached were used to discriminate between polymerases and nucleosomal particles. The results suggest that nucleosomes are absent in heavily transcribed chromatin regions but are reformed after inactivation. In contrast to the findings with inactivated nucleolar genes, in lampbrush chromosome loops the beaded nucleosomal configuration appears to be assumed also in regions within transcriptional units that, perhaps temporarily, are not involved in transcription.

Introduction

In most eucaryotic organisms, the bulk of the nuclear chromatin is organized in repeating nucleoprotein subunits, the nucleosomes or " $\nu$ bodies" (Kornberg, 1974, 1977; Olins and Olins, 1974; Oudet, Gross-Bellard and Chambon, 1975; Woodcock, Safer and Stanchfield, 1976a; Finch et al., 1977). It is still a matter of debate, however, whether this specific configuration primarily reflects the structure of inactive chromatin or is also present in portions of the genome that are actively engaged in transcription (for discussion, see Gottesfeld, Murphy and Bonner, 1975; Garel and Axel, 1976; Weintraub and Groudine, 1976; Foe, Wilkinson and Laird, 1976; Franke et al., 1976a; Kuo, Sahasrabuddhe and Saunders, 1976; Laird et al., 1976; Brown et al., 1977). An answer to the question whether the chromatin containing transcribed DNA sequences is condensed into nucleosomes or is extended into a different non-nucleosomal form is certainly of basic importance in our attempts to understand the mechanisms involved in the regulation of gene expression.

The electron microscopic examination of chromatin material spread directly after isolation in low salt buffers (Miller and Beatty, 1969; Miller and Bakken, 1972) is an adequate method for the demonstration of nucleosomal arrays both in eucaryotic chromatin (for example, Olins and Olins, 1974; Rattner, Branch and Hamkalo, 1975; McKnight and Miller, 1976; Foe et al., 1976; Franke et al., 1976a; Laird et al., 1976; Woodcock et al., 1976a) and in SV40 chromatin (for references and discussion, see Müller et al., 1978). Using this method, various investigators have shown the absence, or reduction in numbers, of nucleosomes in transcriptionally active nucleolar chromatin, not only in heavily transcribed pre-rRNA genes, but also in regions of reduced density of transcriptional complexes and in the apparent spacer intercepts. These investigators have concluded that in these situations, the DNA is in an almost extended configuration (for discussion, see Foe et al., 1976; Franke et al., 1976a; Laird et al., 1976; Trendelenburg et al., 1976; Woodcock et al., 1976b; McKnight, Bustin and Miller, 1977; Scheer et al., 1977). For non-nucleolar genes, the situation observed with this method appears to be somewhat different. Nucleosomes are obviously absent in regions displaying a high packing density of RNA polymerase B particles, such as in the loops of 


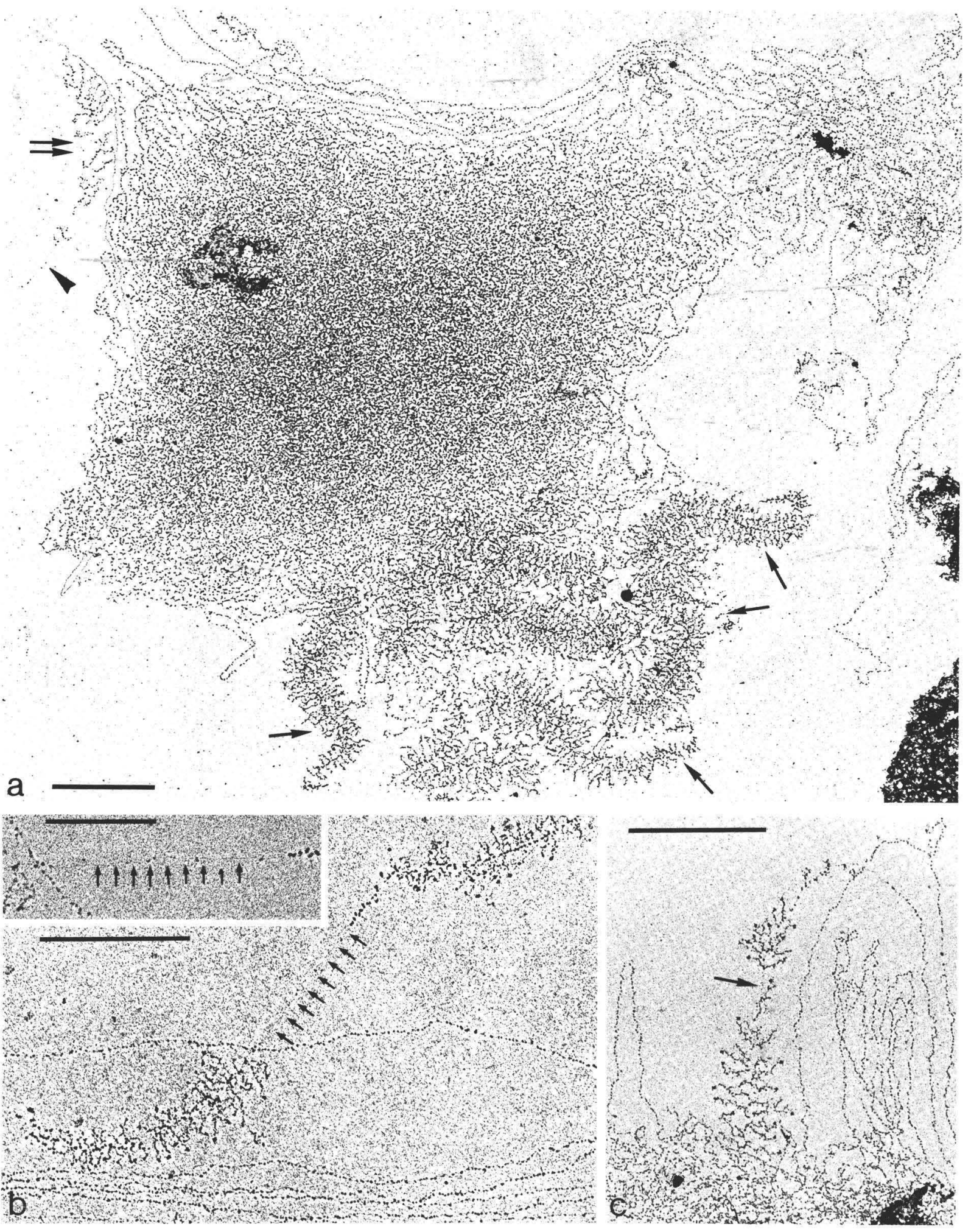

Figure 1. Aggregates of Mostly Inactive Nucleolar Chromatin

Spread preparations were prepared from maturing (a and b) or previtellogenic (c) oocytes of $T$. alpestris (a and $c$ ) and $X$. laevis (b). The continuously beaded appearance of the highly aggregated chromatin fibrils, free of transcriptional complexes, contrasts to the smooth character of transcribed regions. Some fully active pre-rRNA genes are denoted in (a) by arrows. Lateral fibril-free portions within transcribed regions ("gaps") are also nonbeaded [for example, double arrow in (a) and arrow in (c)], as well as the apparent spacer intercepts between matrix units [denoted by the arrowhead in (a) and by small arrows in (b); this situation is illustrated at higher magnification in the insert of (b)]. Bars $=1 \mu \mathrm{m}$, except for the insert of (b) $(0.5 \mu \mathrm{m})$. 

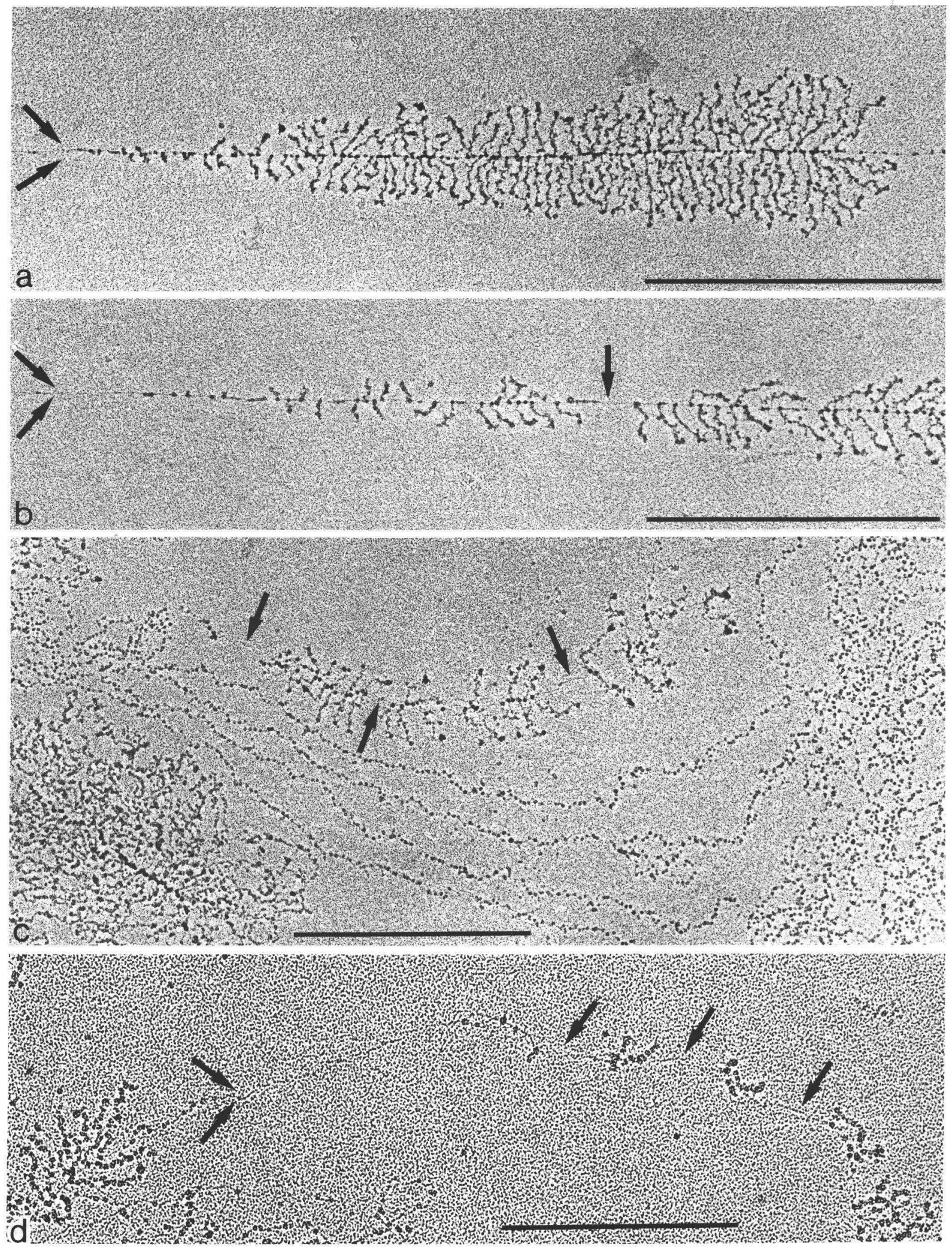

Figure 2. Transcribed Pre-rRNA Genes with Different Densities of the Transcriptional Complexes

Spread preparations ("pH 9 water") were made from growing (a) and mature oocytes (b-d) of T. alpestris (a, b and d) and X. laevis (c). An almost maximally active gene is densely covered with lateral fibrils (a). Progressive reduction of transcriptional complexes is illustrated in (b-d). The axes of the resulting "gaps" (arrows) as well as the spacer intercepts (pairs of arrows) are smooth and thin in contrast to adjacent totally inactive strands of nucleolar chromatin with the typical beaded organization (lower part of c). Bars $=1 \mu \mathrm{m}$. 
lampbrush chromosomes of amphibian oocytes and the primary nucleus of the the green alga Acetabularia, and in the putative silk fibroin gene region of Bombyx mori silk gland (Franke et al., 1976a; McKnight, Sullivan and Miller, 1976; Scheer et al., 1976a). In chromatin strands of much reduced lateral fibril density, however-that is, reduced coverage with transcription complexesparticles of nucleosomal size and staining properties have been reported (Kierszenbaum and Tres, 1975; Foe et al., 1976; Laird et al., 1976; McKnight et al., 1977)

This paper describes the appearance of chromatin regions during progressive inactivation in both nucleolar and non-nucleolar genes of amphibian oocytes. In addition, the use of a detergent for the discrimination between nucleosome and RNA polymerase particles is illustrated. The numerous nucleoli and chromosome loops of amphibian oocytes are especially suitable for such studies, since pronounced natural variations in their transcriptional activity occur during oogenesis (for example, Davidson, 1976; Scheer, Trendelenburg and Franke, 1976b) and an inhibition of transcription of both classes of genes can be induced in relatively short times by treatment with drugs (for example, Snow and Callan, 1969; Scheer, Trendelenburg and Franke, 1975; Rungger and Crippa, 1977). The results of the present study show that there is a lag period before nontranscribed regions assume the nucleosomal configuration and support the concept that the condensation of DNA into nucleosomal particles is characteristic of inactive chromatin. The observations further suggest that this time lag between inactivation of transcription and nucleosomal packing is greater in the nucleolar prerRNA genes than in the non-nucleolar genes.

\section{Results}

Nuclei of both previtellogenic and full-grown amphibian oocytes synthesize rRNA at a much lower rate than those of mid-oogenic stages (Scheer et al., 1976b). Electron microscopy of spread preparations of the nucleolar chromatin of such early and late oocytes reveals numerous distinct large appregates of chromatin fibers which often show a direct structural continuity with single or groupwise-arranged transcribed pre-rRNA genes [Figure $1 \mathrm{a}$; "matrix units" in the sense of Miller and Beatty
(1969)]. Consequently, such fibrillar aggregates represent amplified nucleolar chromatin in which most of the pre-rRNA genes are inactive. In addition, in such chromatin the active genes are frequently characterized by a reduced packing density of the lateral fibrils that contain the nascent RNA (Scheer et al., 1976b). Under normal preparation conditions [0.5 mM borate buffer ( $\mathrm{pH}$ 8.5-9.0)], the chromatin fibrils of these aggregates appear continuously beaded where they are free from lateral ribonucleoprotein (RNP) fibrils. This is in contrast to the predominantly nonbeaded appearance of the transcribed pre-rRNA genes and the apparently nontranscribed spacer regions interspersed between the active genes (Figures $1 b$ and $1 c$ ).

In stages of maximal transcriptional activitythat is, in mid-oogenesis-nucleolar chromatin shows maximally fibril-covered matrix units in all or almost all pre-rRNA genes (Miller and Beatty, 1969; Scheer et al., 1976b), concomitant with a nonbeaded appearance in both the transcribed matrix unit regions and the spacer intercepts (Franke et al., 1976a). To elucidate the mode and the pattern of the appearance of the beaded nucleolar chromatin, intermediate stages of nucleolar inactivation which occur in post-vitellogenic oocytes (compare Scheer et al., 1976b) were examined in detail. Two situations of inactivation of prerRNA genes should be morphologically distinguished: the formation of matrix units with various degrees of reduced density of lateral fibrils, and the complete absence of lateral fibrils in regions of the chromatin axis which, as concluded from the tandem arrangement of the pre-rRNA genes and the position relative to an adjacent matrix unit, should contain gene sequences. Figure 2 presents a collection of matrix units of rDNA containing chromatin at different states of transcriptional activity. With decreasing numbers of nascent RNP fibrils per unit, there is a progressive increase in the distances between RNA polymerase particles along the rDNA chromatin axis. The resulting intercepts that are free of attached RNA polymerases again reveal a uniformly smooth contour and widths ranging from $30-50 \AA$ (Figures $2 a-2 d$ ). Even in matrix units which contain only a few isolated lateral RNP fibrils, the fibril-free sections appear smooth and cannot be distinguished from the adjacent spacer regions (for example, Figure $2 \mathrm{~d}$ ). In contrast, totally inactive-that is, fibril-free, nu-

Figure 3. Structural Continuity between Smooth and Transcribed Regions and Beaded and Nontranscribed Regions of Nucleolar Chromatin Strands

All preparations were made from mature oocytes of T. alpestris (a), T. cristatus (b and c) and X. laevis (d). The arrow in (a) denotes the site of transition between the transcribed (left) and the inactive (right) chromatin fibril. The density of the "beads" appears to be not maximal in that region. The beaded organization is recognized only where chromatin intercepts, including several repeating units, are totally free of transcriptional complexes [(b) the regular bead-like pattern next to the transcribed portion is shown at higher magnification in (c)]. The single active gene shown in (d) (arrow) is adjacent to masses of otherwise inactive and beaded nucleolar chromatin strands. Bars $=1 \mu \mathrm{m}$. 

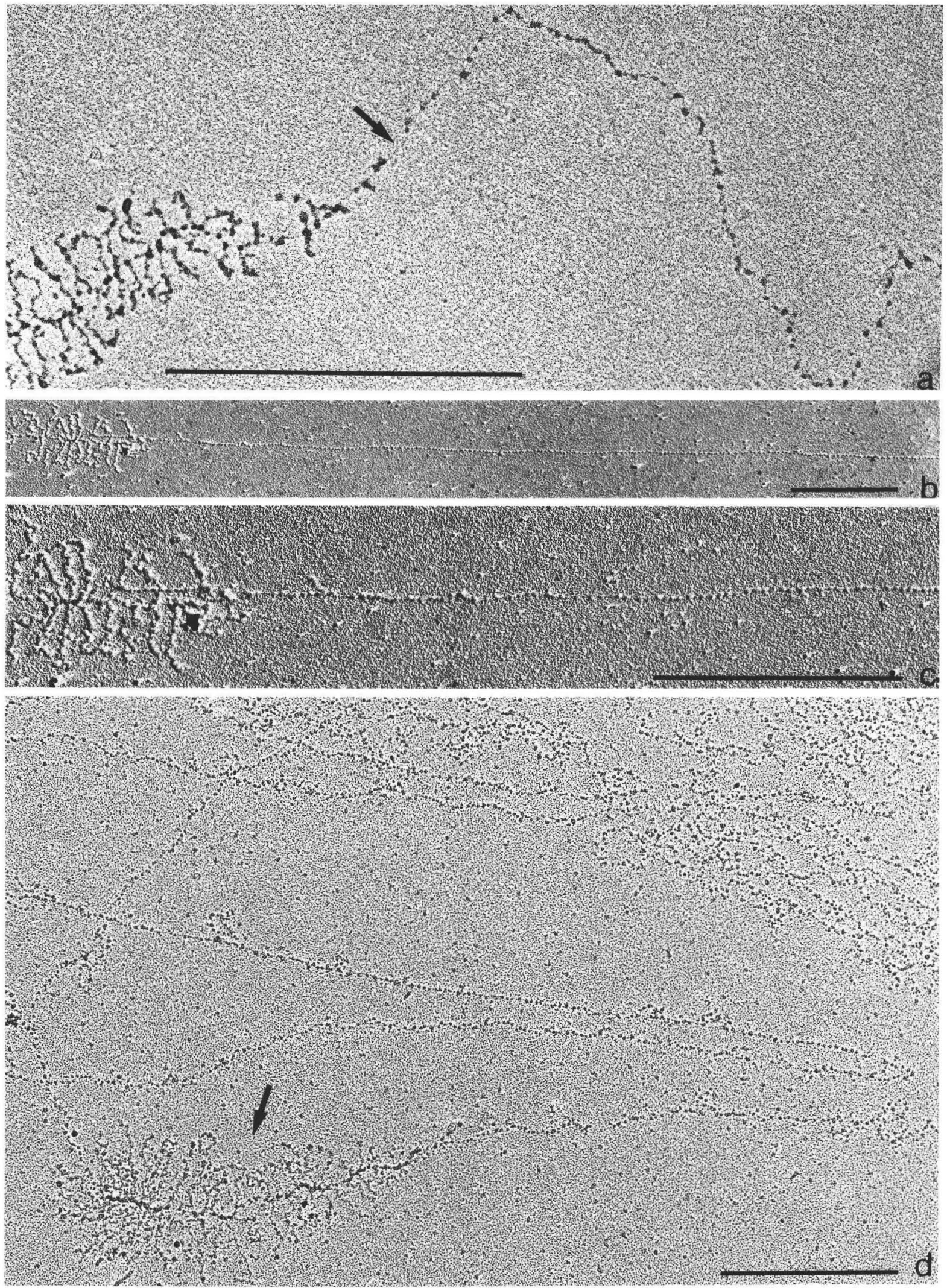
cleolar chromatin axes that are closely adjacent on the same specimen grid - invariably show the characteristic "beads-on-a-string" pattern (for example, Figure 2c). In addition, in aggregates of nucleolar chromatin in which inactive genes predominate, extended axial intercepts devoid of transcriptional complexes and with a beaded appearance are sometimes seen in direct continuity with transcribed gene regions - that is, normal matrix units with a smooth and thin axis (Figures $3 a-3 d$ ). In such nucleoli, the beaded pattern often begins immediately next to the terminal RNA polymerase particles of such a matrix unit (Figures $3 b-3 d$ ). This indicates that in such cases not only adjacent gene units but also spacer regions adjacent to a transcribed matrix unit are in the beaded configuration, in contrast to the smooth character of the apparent spacer intercepts which are located between two actively transcribed matrix units (for example, Figure 1b; compare also Franke et al., 1976a; Scheer et al., 1977).

Actinomycin at concentrations of $25 \mu \mathrm{g} / \mathrm{ml}$ blocks the transcription of rDNA in growing amphibian oocytes and, within a short time, results in a premature release of the transcriptional complexes from the chromatin axes (Scheer et al., 1975). This process seems to be cooperative since often groups of adjacent transcriptional complexes are released which, in the initial stages of actinomycin $D$ action, lead to the formation of gaps within the matrix units (Figure 4a; compare Scheer et al., 1975). In such gaps, corresponding to fibrildepleted regions, most of the axis reveals a smooth and nonbeaded character (Figure 4a). Even when only a few lateral fibrils are left, the axis still exhibits a predominantly smooth contour (Figure 4a). Complete loss of transcriptional complexes, however, as is observed after a sufficient time of drug action, often results in a change from the smooth to the beaded configuration (Figure $4 a$ ). Prolonged action of actinomycin $D$ ultimately induces a situation comparable to that seen in untreated mature oocytes: most of the nucleolar chromatin is free of transcriptional complexes and exhibits an uninterrupted beaded configuration, tends to aggregate into large fibrillar masses, and only occasionally shows some still active pre-rRNA genes (Figure 4b).

The beaded pattern of the inactivated nucleolar chromatin is indistinguishable from that of the almost completely inactive chromatin of hen erythrocyte nuclei (Zentgraf, Scheer and Franke, 1975) that was spread under identical conditions (Figure 5a). Nucleosomes, however, are similar in size and staining properties to RNA polymerase molecules (for references, see Franke et al., 1976a). If the particles present in hen erythrocyte chromatin actually represent nucleosomes, they should be expected to be disorganized under conditions favoring the dissociation of histones from the DNA. The ionic detergent Sarkosyl has been chosen as an especially favorable dissociating agent since it has been shown to remove most of the chromatin protein without affecting already initiated transcriptional complexes (for example, Gariglio, Buss and Green, 1974; Green, Buss and Gariglio, 1975). When chromatin from hen erythrocytes is incubated with increasing concentrations of Sarkosyl under low salt conditions and the released proteins are removed by ultracentrifugation or chromatography on Bio-Gel columns, it is found that the protein/DNA ratio of the remaining nucleoprotein decreases progressively (Figure 6a). At a detergent concentration of $0.5 \%$, about $80 \%$ of the total chromatin-associated protein is solubilized. The analysis of the retained proteins on SDS-containing polyacrylamide gels in untreated and Sarkosyl-extracted chromatin shows that the detergent most effectively releases various nonhistone proteins and the histone classes $\mathrm{H} 1$ and $\mathrm{H} 5$; all other histones are apparently affected to a similar extent (Figures $6 \mathrm{~b}$ and $6 \mathrm{c}$ ). This nearly uniform solubilization of histones $\mathrm{H} 2$ to $\mathrm{H} 4$ also excludes the possibility that the treatment with Sarkosyl preserves DNA complexes of histones $\mathrm{H} 3$ and $\mathrm{H} 4$ which have been shown to be sufficient to generate nucleosome-like particles (Sollner-Webb, Camerini-Otero and Felsenfeld, 1976; Bina-Stein and Simpson, 1977). The commercial dishware detergent "Joy," which was introduced by Miller and Bakken (1972) for facilitated dispersal of the nuclear contents of mammalian cells, used at a concentration of $0.3 \%$ (as for electron microscopic spreadings; for example, Miller and Bakken, 1972; Kierszenbaum and Tres, 1975; Puvion-Dutilleul et al., 1977), also releases about $75 \%$ of the proteins from hen erythrocyte chromatin, resulting in a protein/DNA ratio of only 0.5 and a similar displacement of histones.

Figure 4. Appearance of Nucleolar Chromatin after Release of Transcriptional Complexes and Structural Rearrangement Induced by Actinomycin D

Growing (mid-oogenic) oocytes of T. cristatus (a) and T. alpestris (b) were incubated in the presence of $25 \mu \mathrm{g} / \mathrm{ml}$ actinomycin D. Spread preparations were made after $30 \mathrm{~min}$ (a) or $45 \mathrm{~min}$ (b). The release of transcriptional complexes [a typical resulting gap is indicated by the double arrow in (a)] is not immediately followed by a structural alteration of the chromatin axis. Note the apparently smooth contour of the gene region with only two transcriptional complexes still attached [arrows in (a) and insert]. A beaded pattern, however, is seen in the adjacent region denoted by the bracket. After prolonged exposure to the drug, most of the inactivated chromatin consists of highly aggregated, beaded fibrils which sometimes still show their organization into granular higher order structures [arrows in (b)]. (DA) dense aggregate. Bars $=1 \mu \mathrm{m}$. 


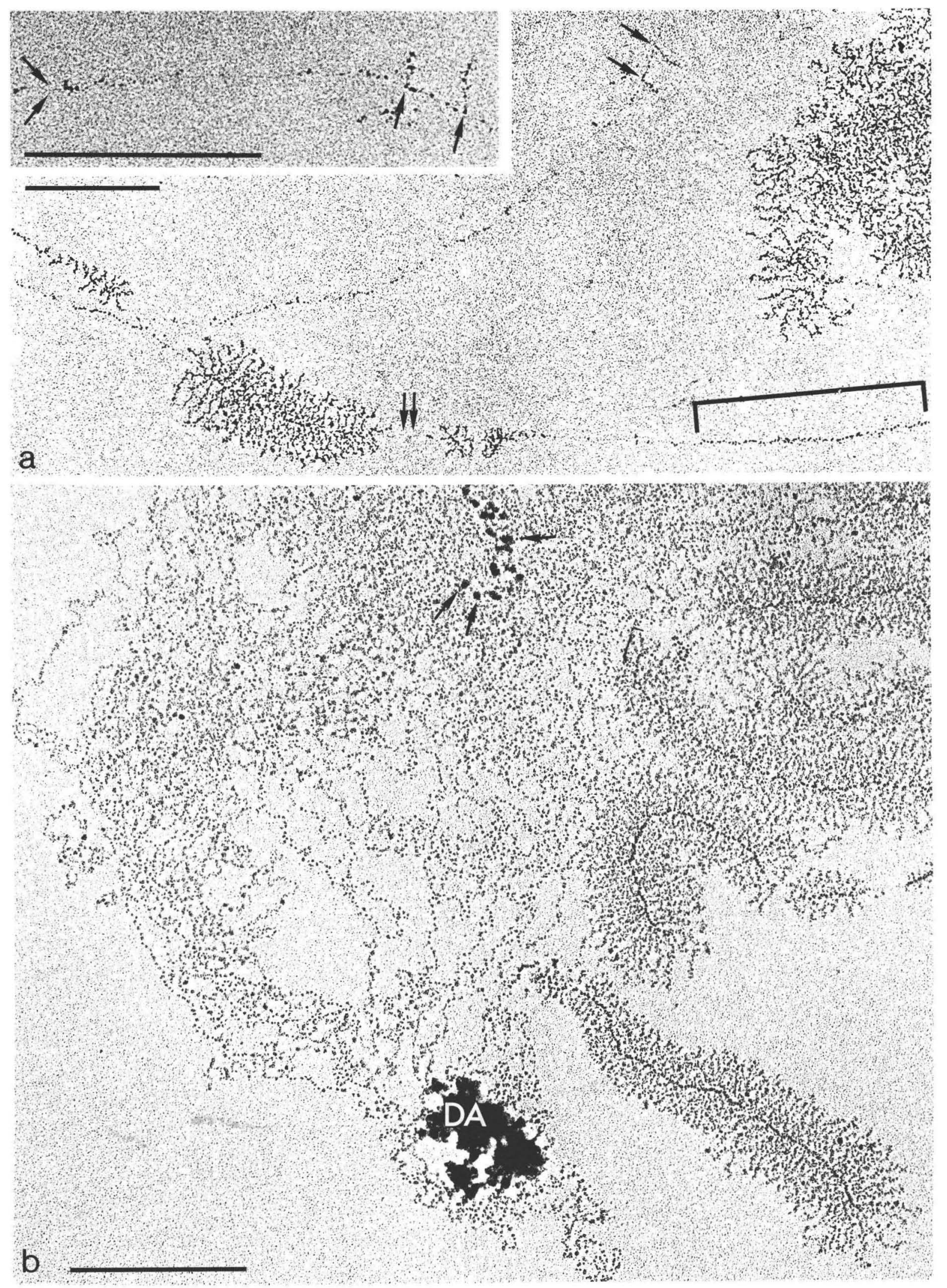



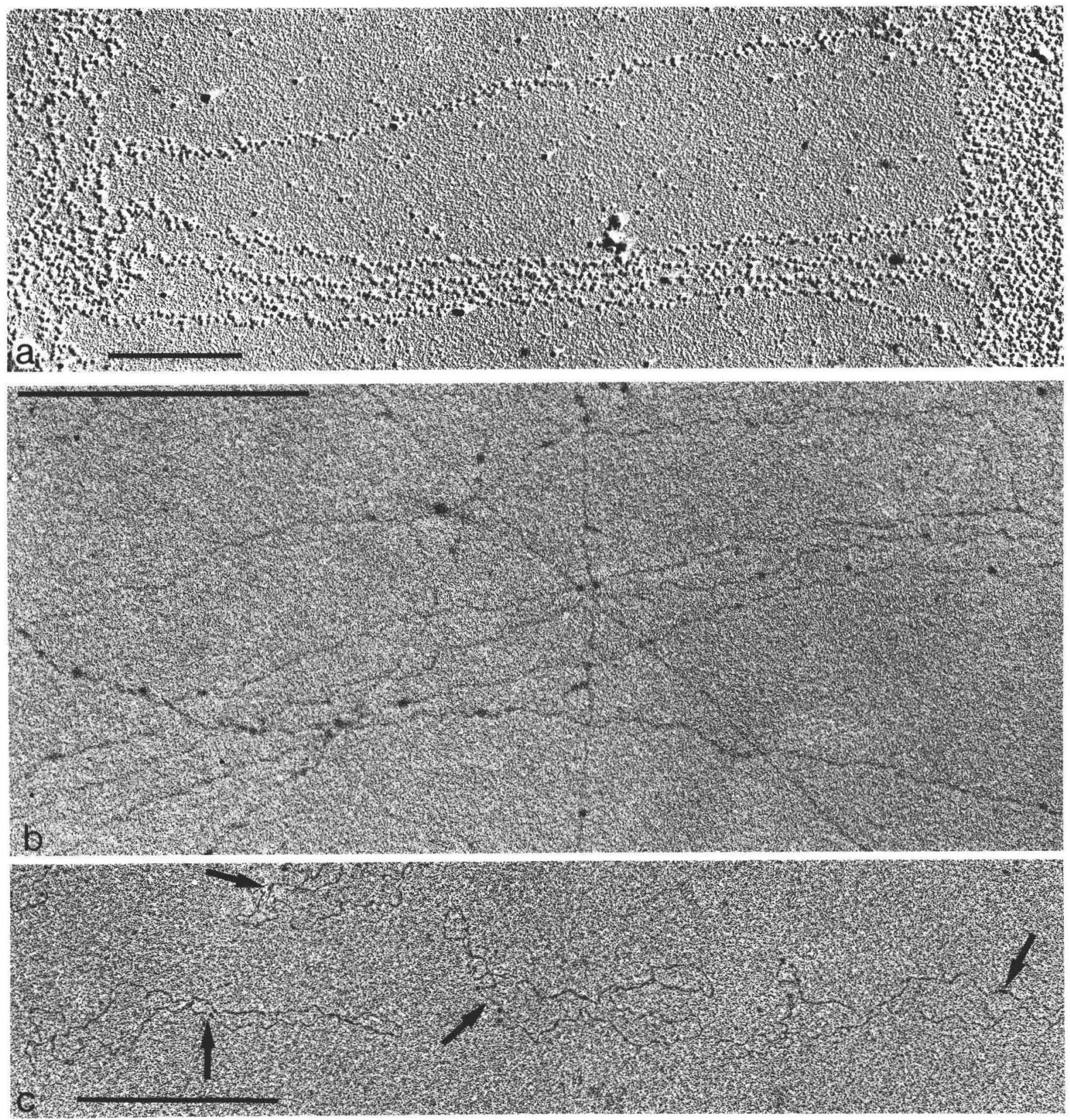

Figure 5. Disintegration of Nucleosomes by the Action of Sarkosyl

Chromatin from hen erythrocytes shows the characteristic beaded appearance when dispersed and spread in "pH 9 water" (a). In the presence of $0.5 \%$ Sarkosyl NL-30, however, the chromatin fibrils are much thinner and smooth (b). Under these conditions, most of the chromatin protein is removed. It should be noted that completely protein-free DNA can also be visualized with the spreading method used in the present study as demonstrated in (c): the arrows point to DNA circles of the bacteriophage PM-2 (provided by Dr. H. Zentgraf). Bars $=0.5 \mu \mathrm{m}$.

When erythrocyte chromatin is dispersed in the presence of Sarkosyl at concentrations of $0.5,0.75$ or $1 \%$, the regular beaded organization of well spread fibers is no longer visible, in agreement with the biochemical determinations, but instead very thin and smooth fibrils are seen which often tend to aggregate laterally (Figure $5 b$ ). It should be emphasized in this connection that, under the centrifugation and staining procedures routinely used in the preparations described here, totally protein-free DNA can well be visualized, as is demonstrated in Figure 5c for viral PM-2 DNA circles.

In contrast to the nucleosomal particles, the transcriptional complexes are highly stable in the presence of Sarkosyl. This differential stability is illustrated in spread preparations of the amplified nucleoli from mature oocytes of urodelan Triturus cristatus and anuran Xenopus laevis amphibia (Fig- 
ures $7 \mathrm{a}$ and $7 \mathrm{~b})$. Matrix units are still clearly recognized after Sarkosyl treatment. The contrast of the lateral fibrils is somewhat reduced, but the basal
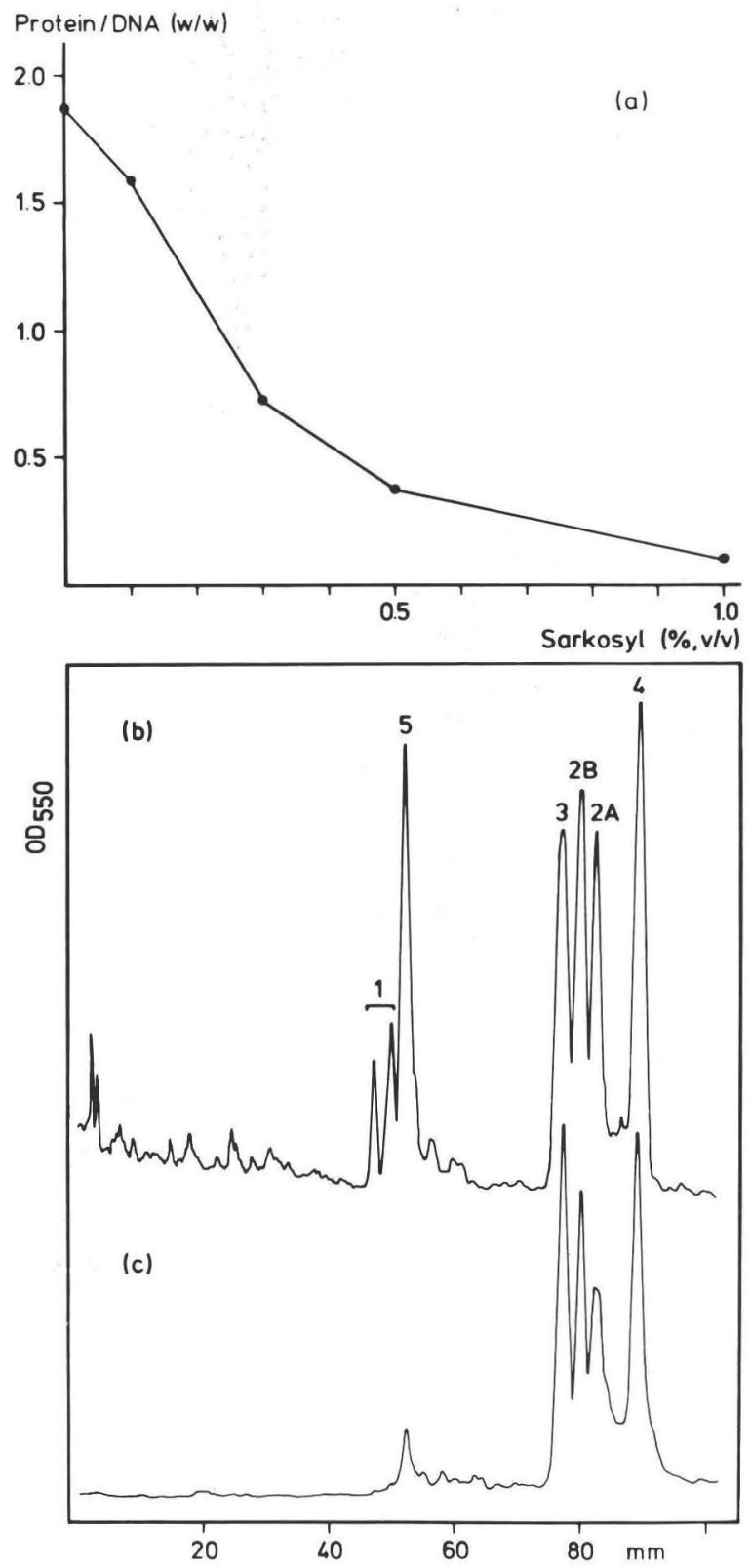

Figure 6. Effect of Sarkosyl on the Protein Content and Composition of Chromatin

With increasing Sarkosyl concentration, most of the protein is displaced from the DNA. Each point in (a) represents the mean value of at least five independent determinations (see Experimental Procedures). Proteins bound to erythrocyte chromatin dispersed in $0.5 \mathrm{mM}$ borate buffer alone (b) and with additional $0.5 \%$ Sarkosyl NL-30 (c) were also analyzed by gel electrophoresis. The gel scans show the preferential extraction of many of the nonhistone proteins as well as of histones $\mathrm{H} 1$ and $\mathrm{H} 5$ at moderate concentrations of Sarkosyl. The numbers above the peaks indicate the specific histone class $(\mathrm{H} 1, \mathrm{H} 2 \mathrm{~A}, \mathrm{H} 2 \mathrm{~B}, \mathrm{H} 3, \mathrm{H} 4, \mathrm{H} 5)$. The sample shown in (c) contained much more DNA than that analyzed in (b).
RNA polymerases stand out as very electron dense particles (Figure 7a; compare Scheer et al., 1977). These residual matrix units are seen next to, and often in structural continuity with, rDNA-containing fibrils free of transcriptional complexes which are uniformly thin (20-40 $\AA$ ) and do not reveal a beaded configuration of nucleosomal size. As in hen erythrocyte chromatin, therefore, the beaded appearance of transcriptionally inactive nucleolar chromatin visualized under "normal" spreading conditions is disorganized by the action of Sarkosyl, thus excluding a RNA polymerase nature and indicating its nucleosomal character.

As with the nucleolar genes, many non-nucleolar genes also seem to go through a cycle of transcriptional activation and inactivation during amphibian oogenesis. In stages of maximal loop extension - that is, during the so-called lampbrush chromosome stage-the loops appear as axes that are fully or partly covered with matrix units which contain transcriptional units of non-nucleolar genes, probably including some for pre-mRNAs (for detailed descriptions and nomenclature, see Scheer et al., 1976a). In such actively transcribed loops, the axis of the matrix units appears thin and smooth - that is, without particles of nucleosomal size located in between the polymerases (Figure 8a; see also Miller and Bakken, 1972; Franke et al., 1976a; Scheer et al., 1976a) The apparently nontranscribed spacer regions in such actively transcribed loops also contain few, if any, nucleosomal particles (same references). This is in contrast to the beaded chromatin fibrils contained in adjacent chromomeric material (Figure 8a). In later stages of oogenesis, chromosome loops are progressively retracted, concomitant with reduced transcription. Correspondingly, when maturing oocytes of amphibia are examined, many chromosome loop axes with only a few widely distant lateral fibrils are recognized. The use of Sarkosyl as a probe for characterizing the structure and composition of the lampbrush chromosome loops is illustrated in Figure 8. Figure 8a presents part of a chromomeric region of a lampbrush chromosome, spread without detergent, which is composed of numerous fibrils with a typically beaded appearance. A lateral loop axis, covered by a long and uninterrupted series of densely spaced lateral fibrils of increasing lengths, can be seen to extend from this chromomeric region (for further details of various arrangements of transcriptional units in such loops, see Scheer et al., 1976a). The packing density of the nascent RNP fibrils in such non-nucleolar transcription units is close to maximal and comparable to that of fully active pre-rRNA genes. When lampbrush chromosomes are prepared from almost fullgrown oocytes, however, most of the loops are in the process of retraction and show drastically re- 


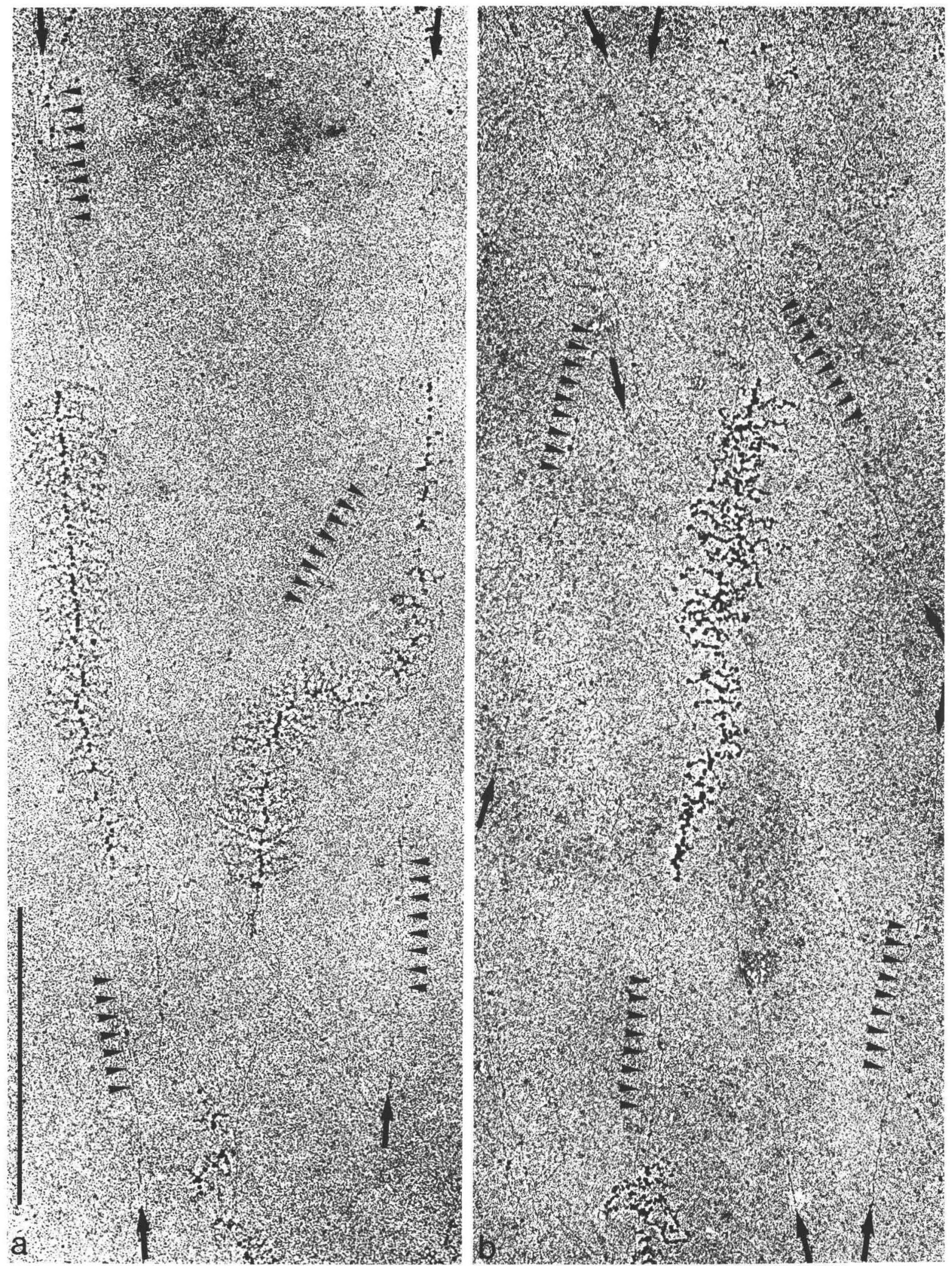

Figure 7. Nucleolar Chromatin from Mature Oocytes Spread in the Presence of $0.5 \%$ Sarkosyl

Matrix units of actively transcribed pre-rRNA genes are still clearly recognized under such conditions, and the RNA polymerase Acontaining particles appear with enhanced relative contrast in spread preparations of $T$. cristatus (a) and $X$. laevis (b) oocytes. The predominant nontranscribed chromatin appears as very thin and smooth axes, some of which are denoted by arrows and arrowheads. Bar 
duced packing densities of the nascent RNP fibrils. In such stages of much reduced activity, the now conspicuous fibril-free sections almost invariably show the typical beaded configuration (Figures $8 \mathrm{~b}$ and $8 \mathrm{c}$ ). These beaded structures in loop chromatin regions between the distant transcriptional complexes, however, are lost after treatment with $0.5 \%$ Sarkosyl NL-30 (Figure $8 \mathrm{~d}$ ), in contrast to the RNA polymerase B-containing particles at the bases of the lateral fibrils. In such Sarkosyl-treated preparations, the uniformly thin loop axis is similar to that of the Sarkosyl-extracted nucleolar chromatin axes described above.

\section{Discussion}

Electron microscopy of spread preparations of chromatin allows a correlation of the structural organization of defined portions of chromatin fibrils with their specific transcriptional activity. Transcriptional activity can be quantitatively described by the density of lateral fibrils along the chromatin axis which, at least in the case of the amplified pre-rRNA genes in amphibia, is well correlated with the rate of rRNA synthesis (Scheer et al., 1976b). A transcriptional complex can usually be identified in spread preparations by the presence of a lateral fibril attached to a chromatinassociated particle, $12-15 \mathrm{~nm}$ in diameter, that contains the RNA polymerase. Nascent RNP fibrils containing RNA chains of $<0.15 \times 10^{6}$ dalton molecular weight, however, are not expected to be resolved by this technique (compare Franke et al., 1976b), and consequently, transcriptional complexes with such short RNA chains would appear as "beads" hardly distinguishable from nucleosomes. In addition, template-bound RNA polymerases that occur in an initiated but strongly repressed state (for example Gariglio et al., 1974; Green et al., 1975; Krüger and Seifart, 1977) might also appear as "chromatin beads." It does not seem justified, therefore, to interpret $80-130 \AA$ particles attached to a chromatin axis as nucleosomes simply on the basis of their size. Treatment with the anionic detergent Sarkosyl in concentrations ranging from $0.5-1 \%$, however, allows one to discriminate between RNA polymerases and nucleosomes, due to the specifically high resistance of transcriptional complexes to this treatment.

Several observations have indicated that actively transcribed regions of chromatin are not condensed into nucleosomes but extended to about the length of the DNA in B conformation (for references, see the Introduction; Miller and Beatty, 1969; Scheer, Trendelenburg and Franke, 1973). Extended nonbeaded states of chromatin with the full nucleosomal histone complement have so far been described only in high urea concentrations (for references, see Olins et al., 1977). The findings in various laboratories that transcriptional complexes and/or sequences complementary to transcriptional products can be recovered in the nucleosomal fraction obtained by nuclease digestions (for example, Lacy and Axel, 1975; Gottesfeld et al., 1975; Garel and Axel, 1976; Mathis and Gorovsky, 1976; Kuo et al., 1976; Piper et al., 1976; Reeves and Jones, 1976; Reeves, 1976, 1977; Brown et al., 1977) are not contradictory to the conclusion that nucleosomal beads are absent in chromatin regions engaged in transcription. It has been shown that nucleosome-sized fragments are also obtained from digestion with micrococcal nuclease when chromatin is unfolded as, for example, in high urea concentrations (Jackson and Chalkley, 1975; for related observations, see also Woodcock and Frado, 1977; Oudet, Spadafora, and Chambon, 1977). The adenovirus genome, which is complexed with nonhistone proteins, also appear to be extended and can be cleaved into fragments of a basic repeat unit of about 200 base pairs (Miller and Hodge, 1975; Corden, Engelking and Pearson, 1976). Moreover, in most of transcriptionally active chromatin, a maximal coverage with transcription complexes cannot be assumed.

The masses of the predominantly extrachromosomal nucleolar chromatin of amphibian oocytes are largely inactive in transcription and contain only few nascent RNP fibrils in previtellogenic stages (Scheer et al., 1976b). This chromatin appears for the most part in typically beaded chains characteristic of nucleosomal organization (see also Figure 1c). With progressive transcription during oogenesis, maximal fibril density is attained, concomitant with a smoothly contoured, non-nucleosomal appearance in all the chromatin containing the pre-rRNA genes as well as the spacer intercepts (compare Franke et al., 1976a, 1976b; Scheer et al., 1976b). Then, in maturing oocytes, the transcriptional activity of the rDNA-containing chromatin ceases dramatically, which is again correlated with a reduced density of both lateral fibrils and active genes, respectively (Scheer et al., $1976 b)$. During this transition from maximally active to relatively inactive states, an increasing proportion of the nucleolar chromatin appears to be condensed into nucleosomes and becomes indistinguishable from other portions of inactive chromatin. This demonstrates that changes in transcriptional activity are paralleled by conformational changes of the nucleolar chromatin that can be visualized by electron microscopy. A similar change is observed when the maximally active nucleolar chromatin of mid-oogenic stages is inhibited by treatment with actinomycin D. Interestingly, the transition to the extended, nonbeaded chromatin structure is not restricted to the tran- 

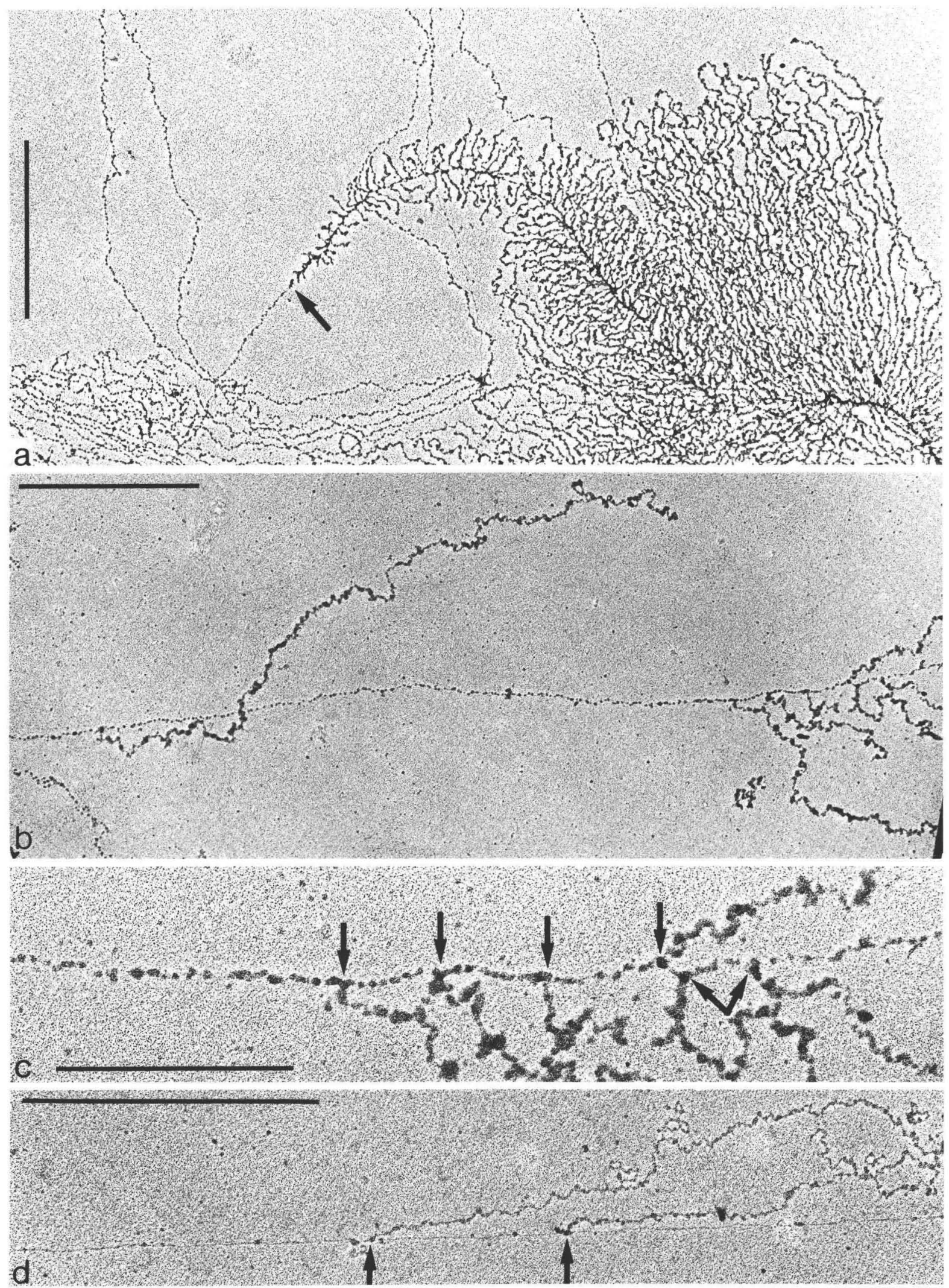
scriptional complexes themselves and their immediate environment, but also takes place, and is maintained, in fibril-free intragenic (compare Foe et al., 1976; Laird et al., 1976) and spacer regions. This suggests that the conformational change from nucleosomal packing to the extended state is not directly associated, by space and time, with the transcriptional event. Rather, the unravelling of nucleosomes precedes the transcription of rDNA, and rearrangement into nucleosomes follows the cessation of transcription with a certain time lag [a similar conclusion has been reached in a study of the embryogenesis of the milkweed bug by Foe (1977)].

A similar progressive increase of nucleosomal particles is also observed during the inactivation of lampbrush chromosome loops in later stages of oogenesis and after drug treatment. In contrast to the situation described in nucleolar genes, however, nucleosomes here can also be seen in the proximity of the sparse transcriptional complexes. This, however, appears to be restricted to units of low lateral fibril density, indicative of low transcription rates (compare Angelier and Lacroix, 1975). Similar observations have been made in sparsely fibril-covered-that is, only moderately activechromatin strands of a variety of somatic cells (for example, Foe et al., 1976; Laird et al., 1976; Foe, 1977; McKnight et al., 1977). The observed different extents of nonbeaded chromatin in stages of reduced transcriptional activity of nucleolar and non-nucleolar genes suggest that the rearrangement of the nucleosome after the passage of a transcriptional event is faster in the non-nucleolar transcription units. The observed charrges of chromatin structure during transcription are compatible with reported biochemical differences between active and inactive chromatin (for example, Garel and Axel, 1976; Weintraub and Groudine, 1976; Reeves, 1976, 1977; Bellard, Gannon and Chambon, 1977). The present observations, however, suggest that the structural changes involved in the predisposition of the chromatin to transcription are much more profound than the changes envisaged in some recent models (for example, Tsanev and Petrov, 1976; Weintraub, Worcel and Alberts, 1976).

\section{Experimental Procedures}

\section{Preparation of Chromatin for Electron Microscopy}

Nuclei were manually isolated from mid-sized (lampbrush chromosome stage) or almost full-grown oocytes obtained from Xenopus laevis, Triturus alpestris and T. cristatus carnifex in the " $5: 1$ medium" (5 parts $0.1 \mathrm{M} \mathrm{KCl}$ and 1 part $0.1 \mathrm{M} \mathrm{NaCl}$ ) buffered with $10 \mathrm{mM}$ Tris- $\mathrm{HCl}(\mathrm{pH}$ 7.2). Two nuclei each were immediately transferred into a drop of $0.5 \mathrm{mM}$ borate buffer $(\mathrm{pH} 8.5-9.0)$ (" $\mathrm{pH}$ 9 water") and placed on a siliconized glass slide at about $10^{\circ} \mathrm{C}$. Usually the nuclear envelope broke up due to the rapid swelling of the nuclear contents, or it was punctured with a fine needle. Alternatively, lampbrush stage oocytes $(0.6-0.8 \mathrm{~mm}$ in diameter) were incubated in a culture medium in the presence of $25 \mu \mathrm{g} / \mathrm{ml}$ actinomycin D (for details, see Scheer et al., 1975). After 30 or 45 $\mathrm{min}$, nuclei were isolated and processed as above.

Although the amplified nucleolar chromatin could be easily discriminated in spread preparations from the chromosomes with their unique lampbrush configuration, control spreadings were performed with fractions enriched in nucleoli or lampbrush chromosomes. After isolation of nuclei in the "5:1 medium," the nuclear envelope was punctured and removed from the gelified nucleoplasm which served as a source for lampbrush chromosomes. In growing oocyte stages, independent of a preceding brief treatment with actinomycin D (Scheer et al., 1975), most of the amplified nucleoli were stably associated with the inner nuclear membrane, whereas in nearly mature oocytes, only a small proportion of the nucleoli remained in association with the envelope. In any case, in both oocyte stages the isolated nuclear envelope contained chromosome-free nucleoli, although with greatly different yields.

Hen erythrocytes were obtained by gentle centrifugation (for 5 $\mathrm{min}$ at $200 \times \mathrm{g}$ ) of blood diluted with physiological saline containing $2 \%$ of the anticoagulate Liquemin (Liquemin 5000; HoffmannLa Roche, Grenzach, Federal Republic of Germany). The erythrocytes were washed twice in $0.9 \% \mathrm{NaCl}$, then lysed by incubation in " $\mathrm{pH} 9$ water," and finally gently homogenized with a motordriven Potter-Elvehjem homogenizer. After $30 \mathrm{~min}$ at $4^{\circ} \mathrm{C}$, the whitish, flocculent crude chromatin was pelleted (at $3500 \times \mathrm{g}$ for $10 \mathrm{~min}$ ) and finally dispersed in a large volume of "pH 9 water." Chromatin solubilized under these low salt conditions with or without added detergents was then centrifuged onto electron microscopic grids and stained according to the method of Miller and Bakken (1972) with the modifications described by Scheer et al. (1973). To enhance the contrast, most of the specimens were rotary-shadowed with platinum/paladium $(80: 20)$ at an angle of $8^{\circ}$. Micrographs were taken with a Zeiss EM-10 electron microscope at $60 \mathrm{kV}$.

Release of Chromatin Proteins by Sarkosyl and "Joy" Crude erythrocyte chromatin was prepared as described above and dissolved in "pH 9 water" to a final concentration of about $350 \mu \mathrm{g}$ DNA per ml by stirring for $2 \mathrm{hr}$. This solution was sheared for 1 min with rotating knives ( 3 runs at 8000 rpm; Fa. Buehler, Tübingen, Federal Republic of Germany) and then centrifuged for $10 \mathrm{~min}$ at $3500 \times \mathrm{g}$. Aliquots $(5 \mathrm{ml})$ of the supernatant were then brought to final Sarkosyl NL-30 concentrations ranging from 0.1 -

Figure 8. Identification of Nucleosomes in Lampbrush Chromosome Loops of T. alpestris in Stages of Reduced Transcriptional Activity During mid-oogenesis, most of the sometimes huge transcriptional units [the arrow in (a) denotes a start region] are densely packed with lateral fibrils. The chromomere region, however, contains aggregates of fibrils with a beaded aspect [lower left of (a)]. In late stages of oogenesis, the density of transcriptional complexes decreases drastically $(b-d)$. The intercepts on the loop axis between the individual distant transcriptional complexes [their basal RNA polymerase B-containing particles are denoted by the arrows in (c)] have a beaded appearance ( $b$ and $c$ ). When such preparations are made in the presence of $0.5 \%$ Sarkosyl, the beaded configuration is destroyed (d), and the loop axis appears as a very thin, nonbeaded fibril. Transcriptional complexes are stable under these conditions [arrows in (d)]. Bars in $(\mathrm{a}, \mathrm{b}$ and $\mathrm{d})=1 \mu \mathrm{m} ;$ in $(\mathrm{c}), \mathrm{bar}=0.5 \mu \mathrm{m}$. 
$1.0 \%$ (NL-30 is a $30 \%$ aqueous solution of sodium lauryl sarcosinate; Ciba-Geigy, Basel, Switzerland) or to $0.3 \%$ with respect to the commercial dishware detergent "Joy" (Proctor and Gamble). To separate the released proteins from the nucleoprotein, the $5 \mathrm{ml}$ aliquots were filtered through a Bio-Gel A-50 m column equilibrated with the same detergent solution at a flow rate of $0.5-1$ $\mathrm{ml} / \mathrm{min}$ at $4^{\circ} \mathrm{C}$. Nucleoprotein eluted as a sharp peak in the exclusion volume (Kleiman and Huang, 1971) and was detected by measuring the absorbance at $260 \mathrm{~nm}$. Alternatively, the erythrocyte chromatin was purified on a Bio-Gel A 50 m column equilibrated with "pH 9 water." Aliquots containing $30 \mu \mathrm{g} D N A / m l$ were then adjusted to different concentrations of Sarkosyl, and the solutions were centrifuged at $40,000 \mathrm{rpm}$ for $20 \mathrm{hr}$ in an SW40 rotor at $4^{\circ} \mathrm{C}$ to sediment the nucleoprotein (compare Ohlenbusch et al., 1967).

\section{DNA and Protein Analyses}

Detergents were removed from the nucleoprotein-containing solutions by extensive uITrafiltration through a PM30 filter (Amicon, Lexington, Massachusetts) with $0.5 \mathrm{mM}$ borate buffer $(\mathrm{pH} 8.8)$. After concentration by ultrafiltration, DNA contents were determined by measurements of the absorbance at $260 \mathrm{~nm}\left(1 \mathrm{~A}_{260}=48\right.$ $\mu \mathrm{g}$ DNA per $\mathrm{ml}$ ) and by the diphenylamine reaction (Burton, 1968). Protein concentrations were determined by absorbance at $230 \mathrm{~nm}$ using the conversion data of Tuan and Bonner (1969) and with the method of Lowry et al. (1951) using bovine serum albumin as a standard. The erythrocyte chromatin purified by agarose gel filtration with " $\mathrm{pH} 9$ water" as the eluting solvent had a protein/DNA (w/w) ratio of 1.87 (compare Zentgraf et al., 1971)

\section{Gel Electrophoresis of Chromatin Proteins}

SDS-polyacrylamide gel electrophoresis was carried out essentially according to Thomas and Kornberg (1975). Appropriate amounts of the nucleoprotein solutions $(30-80 \mu \mathrm{g}$ with respect to protein), eluted from the column or obtained by resuspending the pellets after ultracentrifugation, were dried under nitrogen, dissolved in sample buffer, heated and applied to the gel. After staining with Coomassie blue, the gels were scanned at $550 \mathrm{~nm}$ in a Gilford Spectrophotometer equipped with a linear transport device.

\section{Acknowledgments}

I wish to thank my colleagues Drs. W. W. Franke, M. F. Trendelenburg and $\mathrm{H}$. Zentgraf for their helpful comments and experimental help, as well as Miss Stefanie Winter and Mr. Klaus Mähler for their skillful assistance. This work received support from the Deutsche Forschungsgemeinschaft.

The costs of publication of this article were defrayed in part by the payment of page charges. This article must therefore be hereby marked "advertisement" in accordance with 18 U.S.C. Section 1734 solely to indicate this fact.

Received November 23, 1977; revised December 7, 1977

\section{References}

Angelier, N. and Lacroix, J. C. (1975). Complexes de transcription d'origines nucléolaire et chromosomique d'ovocytes de Pleurodeles waltlii et $\mathrm{P}$. poireti. Chromosoma 51, 323-335.

Bellard, M., Gannon, F. and Chambon, P. (1977). Nucleosome structure. III. Are actively transcribed genes compacted in nucleosomes? Cold Spring Harbor Symp. Quant. Biol. 42, in press.

Bina-Stein, M. and Simpson, R. T. (1977). Specific folding and contraction of DNA by histones $\mathrm{H} 3$ and $\mathrm{H} 4$. Cell 11, 609-618.

Brown, I., Heikkila, J., Silver, J. and Straus, N. (1977). Organization and transcriptional activity of brain chromatin subunits. Biochim. Biophys. Acta 477, 288-294.

Burton, K. (1968). Determination of DNA concentration with diphenylamine. In Methods in Enzymology, 12B, L. Grossman and K. Moldave, eds. (New York: Academic Press), pp. 163-166.
Corden, J., Engelking, H. M. and Pearson, G. D. (1976). Chromatin-like organization of the adenovirus chromosome. Proc. Nat. Acad. Sci. USA 73, 401-404.

Davidson, E. H. (1976). Gene Activity in Early Development (New York: Academic Press).

Finch, J. T., Lutter, L. C., Rhodes, D., Brown, R. S., Rushton, B., Levitt, M. and Klug, A. (1977). Structure of nucleosome core particles of chromatin. Nature 269, 29-36

Franke, W. W., Scheer, U., Trendelenburg, M. F., Spring, H. and Zentgraf, H. (1976a). Absence of nucleosomes in transcriptionally active chromatin. Cytobiologie 13, 401-434.

Franke, W. W., Scheer, U., Spring, H., Trendelenburg, M. F. and Krohne, G. (1976b). Morphology of transcriptional units of rDNA. Exp. Cell Res. 100, 233-244.

Foe, V. E. (1977) Chromatin structure and transcriptional activity: an electron microscopic study of rRNA synthesis. Cold Spring Harbor Symp. Quant. Biol. 42, in press.

Foe, V. E., Wilkinson, L. E. and Laird, C. D. (1976). Comparative organization of active transcription units in Oncopeltus fasciatus. Cell 9, 131-146.

Garel, A. and Axel, R. (1976). Selective digestion of transcriptionally active ovalbumin genes from oviduct nuclei. Proc. Nat. Acad. Sci. USA 73, 3966-3970.

Gariglio, P., Buss, J. and Green, M. H. (1974). Sarkosyl activation of RNA polymerase activity in mitotic mouse cells. FEBS Letters $44,330-333$

Gottesfeld, J. M., Murphy, R. F. and Bonner, J. (1975). Structure of transcriptionally active chromatin. Proc. Nat. Acad. Sci. USA 72, 4404-4408.

Green, M. H., Buss, J. and Gariglio, P. (1975). Activation of nuclear RNA polymerase by Sarkosyl. Eur. J. Biochem. 53, 217225.

Jackson, V. and Chalkley, R. (1975). The effect of urea on staphylococcal nuclease digestion of chromatin. Biochem. Biophys. Res. Commun. 67, 1391-1400

Kierszenbaum, A. L. and Tres, L. L. (1975). Structural and transcriptional features of the mouse spermatid genome. J. Cell Biol. $65,258-270$.

Kleiman, L. and Huang, R. C. C. (1971). Binding of actinomycin D to calf thymus chromatin. J. Mol. Biol. 55, 503-521.

Kornberg, R. D. (1974). Chromatin structure: a repeating unit of histones and DNA. Science 184, 868-871.

Kornberg, R. D. (1977). Structure of chromatin. Ann. Rev. Biochem. 46, 931-954.

Krüger, C. and Seifart, K. H. (1977). RNA polymerases during differentiation of avian erythrocytes. Exp. Cell Res. 106, 446-450. Kuo, M. T., Sahasrabuddhe, C. G. and Saunders, G. F. (1976). Presence of messenger specifying sequences in the DNA of chromatin subunits. Proc. Nat. Acad. Sci. USA 73, 1572-1575.

Lacy, E. and Axel, R. (1975). Analysis of DNA of isolated chromatin subunits. Proc. Nat. Acad. Sci. USA 72, 3978-3982.

Laird, C. D., Wilkinson, L. E., Foe, V. E. and Chooi, W. Y. (1976). Analysis of chromatin-associated fiber arrays. Chromosoma 58 , 169-192.

Lowry, O. H., Rosebrough, N. J., Farr, A. L. and Randall, R. J. (1951). Protein measurement with the folin phenol reagent. J. Biol. Chem. 193, 265-275.

McKnight, S. L. and Miller, O. L., Jr. (1976). Ultrastructural patterns of RNA synthesis during early embryogenesis of Drosophila melanogaster. Cell 8, 305-319.

McKnight, S. L., Sullivan, N. L. and Miller, O. L. (1976). Visualization of the silk fibroin transcription unit and nascent silk fibroin molecules on polyribosomes of Bombyx mori. In Progress in Nucleic Acid Research and Molecular Biology, 19, W. E. Cohn and E. Volkin, eds. (New York: Academic Press), p. 313-318. McKnight, S. L., Bustin, M. and Miller, O. L. (1977). Electron 
microscopic analysis of chromosome metabolism in the Drosophila melanogaster embryo. Cold Spring Harbor Symp. Quant. Biol. 42 , in press.

Mathis, D. J. and Gorovsky, M. A. (1976). Subunit structure of rDNA-containing chromatin. Biochemistry 15, 750-755.

Miller, O. L. and Beatty, B. R. (1969). Visualization of nucleolar genes. Science 164, 955-957.

Miller, O. L. and Bakken, A. H. (1972). Morphological studies of transcription. Acta Endocrinol. Suppl. 168, 155-177.

Miller, O. L. and Hodge, L. D. (1975). Visualization of a unique nuclear adenovirus DNA-protein complex. J. Cell Biol. 67, 284a. Müller, U., Zentgraf, H., Eicken, I. and Keller, W. (1977). Higherorder structure of simian virus 40 chromatin. Science, in press.

Ohlenbusch, H. H., Olivera, B. M., Tuan, D. and Davidson, N. (1967). Selective dissociation of histones from calf thymus nucleoprotein. J. Mol. Biol. 25, 299-315.

Olins, A. L. and Olins, D. E. (1974). Spheroid chromatin units ( $\nu$ bodies). Science 183, 330-332.

Olins, D. E., Bryan, P. N., Harrington, R. E., Hill, W. E. and Olins, A. L. (1977). Conformational states of chromatin $\nu$ bodies induced by urea. Nucl. Acids Res. 4, 1911-1931.

Oudet, P., Gross-Bellard, M. and Chambon, P. (1975). Electron microscopic and biochemical evidence that chromatin structure is a repeating unit. Cell 4, 281-300.

Oudet, P., Spadafora, C. and Chambon, P. (1977). Nucleosome structure. II. Structure of SV40 minichromosome and electron microscopic evidence that a nucleosome could be constituted of two half nucleosomes. Cold Spring Harbor Symp. Quant. Biol. 42, in press.

Piper, P. W., Celis, J., Kaltoft, K., Leer, J. C., Nielsen, O. F. and Westergaard, O. (1976). Tetrahymena ribosomal RNA gene chromatin is digested by micrococcal nuclease at sites which have the same regular spacing on the DNA as corresponding sites in the bulk nuclear chromatin. Nucl. Acids Res. 3, 493-505.

Puvion-Dutilleul, F., Bernadac, A., Puvion, E. and Bernhard, W. (1977). Visualization of two different types of nuclear transcriptional complexes in rat liver cells. J. Ultrastruct. Res. 58, 108-117. Rattner, J. B., Branch, A. and Hamkalo, B. A. (1975). Electron microscopy of whole mount metaphase chromosomes. Chromosoma $52,329-338$

Reeves, R. (1976). Ribosomal genes of Xenopus laevis: evidence of nucleosomes in transcriptionally active chromatin. Science $194,529-532$.

Reeves, R. (1977). Analysis and reconstruction of Xenopus ribosomal chromatin nucleosomes. Eur. J. Biochem. 75, 545-560.

Reeves, R. and Jones, A. (1976). Genomic transcriptional activity and the structure of chromatin. Nature 260,495-500.

Rungger, D. and Crippa, M. (1977). The primary ribosomal DNA transcript in eukaryotes. Prog. Biophys. Mol. Biol. 31, 247-269. Scheer, U., Trendelenburg, M. F. and Franke, W. W. (1973). Transcription of ribosomal RNA cistrons. Exp. Cell Res. 80, 175190.

Scheer, U., Trendelenburg, M. F. and Franke, W. W. (1975). Effects of actinomycin $D$ on the association of newly formed ribonucleoproteins with the cistrons of ribosomal RNA in Triturus oocytes. J. Cell Biol. 65, 163-179.

Scheer, U., Franke, W. W., Trendelenburg, M. F. and Spring, H. (1976a). Classification of loops of lampbrush chromosomes according to the arrangement of transcriptional complexes. J. Cell Sci. 22, 503-520.

Scheer, U., Trendelenburg, M. F. and Franke, W. W. (1976b). Regulation of transcription of genes of ribosomal RNA during amphibian oogenesis. J. Cell Biol. 69, 465-489.

Scheer, U., Trendelenburg, M. F., Krohne, G. and Franke, W. W. (1977). Lengths and patterns of transcriptional units in the amplified nucleoli of oocytes of Xenopus laevis. Chromosoma 60, 147167.
Snow, M. H. and Callan, H. G. (1969). Evidence for a polarized movement of the lateral loops of newt lampbrush chromosomes during oogenesis. J. Cell Sci. 5, 1-25.

Sollner-Webb, B., Camerini-Otero, R. D. and Felsenfeld, G. (1976). Chromatin structure as probed by nucleases and proteases: evidence for the central role of histones $\mathrm{H} 3$ and $\mathrm{H} 4$. Cell 9 , 179-193.

Thomas, J. O. and Kornberg, R. D. (1975). An octamer of histones in chromatin and free in solution. Proc. Nat. Acad. Sci. USA 72, 2626-2630.

Trendelenburg, M. F., Scheer, U., Zentgraf, H. and Franke, W. W. (1976). Heterogeneity of spacer lengths in circles of amplified ribosomal DNA of two insect species, Dytiscis marginalis and Acheta domesticus. J. Mol. Biol. 108, 453-470.

Tsanev, R. and Petrov, P. (1976). The substructure of chromatin and its variations as revealed by electron microscopy. J. Microscopie Biol. Cell. 27, 11-18.

Tuan, D. Y. H. and Bonner, J. (1969). Optical absorbance and optical rotatory dispersion studies on calf thymus nucleohistone. J. Mol. Biol. 45, 59-76.

Weintraub, H. and Groudine, M. (1976). Chromosomal subunits in active genes have an altered conformation. Science 193, 848856 .

Weintraub, H., Worcel, A. and Alberts, B. (1976). A model for chromatin based upon two symmetrically paired half-nucleosomes. Cell 9, 409-417.

Woodcock, C. L. F. and Frado, L. L. Y. (1977). Ultrastructure of chromatin subunits during unfolding, histone depletion and reconstitution. Cold Spring Harbor Symp. Quant. Biol. 42, in press.

Woodcock, C. L. F., Safer, J. P. and Stanchfield, J. E. (1976a). Structural repeating units in chromatin. Exp. Cell Res. 97, 101110.

Woodcock, C. L. F., Frado, L. L. Y., Hatch, C. L. and Ricciardiello, L. (1976b). Fine structure of active ribosomal genes. Chromosoma $58,33-39$.

Zentgraf, H., Deumling, B., Jarasch, E.-D. and Franke, W. W. (1971). Nuclear membranes and plasma membranes from hen erythrocytes. J. Biol. Chem. 246, 2986-2995.

Zentgraf, H., Scheer, U. and Franke, W. W. (1975). Characterization and localization of the RNA synthesized in mature avian erythrocytes. Exp. Cell Res. 96, 81-95. 